NOVO HUMANISMO, JUSTIÇA CIDADÃ, ADMINISTRAÇÃO PÚBLICA GERENCIAL, PODER JUDICIÁRIO E INTELIGÊNCIA ARTIFICIAL: uma análise sobre o uso da computação cognitiva pelo Poder Judiciário brasileiro e os seus reflexos nas funções administrativa e jurisdicional à luz do Projeto Victor

NEW HUMANISM, CITIZEN JUSTICE, MANAGERIAL PUBLIC ADMINISTRATION, JUDICIARY AND ARTIFICIAL INTELLIGENCE: an analysis of the use of cognitive computing by the Brazilian Judiciary and its reflections on administrative and judicial functions in the light of the Victor Project

\author{
Anne Shirley de Oliveira Rezende Martins" \\ João Paulo Alves dos Reis \\ Lucas Silva Andrade*
}

\begin{abstract}
Resumo
Tendo como referencial teórico o modelo de Administração Pública Gerencial, procurou-se verificar a contribuição da inteligência artificial para a promoção do novo humanismo e do ideal de Justiça Cidadã. Para tanto, buscou-se aferir se os mecanismos de inteligência artificial estão alinhados, em princípio, ao modelo de Administração Pública Gerencial, analisando a compatibilidade do Projeto Victor do Supremo Tribunal Federal (STF) com o princípio da indelegabilidade da função jurisdicional e os reflexos da utilização da computação cognitiva no exercício das funções administrativa e jurisdicional do Poder Judiciário brasileiro. Analisando os resultados até agora conhecidos do Projeto Victor (STF), restou demonstrado que mecanismos de computação cognitiva são compatíveis com o mencionado modelo de Administração Pública, gerando impactos positivos nas funções administrativa e jurisdicional, sem ferir a proibição de delegação desta última. Nesse sentido, concluiu-se que os sistemas de inteligência artificial contribuem para um futuro melhor do Poder Judiciário brasileiro e para a concretização do novo humanismo e do ideal de Justiça cidadã.
\end{abstract}

Palavras-chave: Administração Pública Gerencial. Poder Judiciário. Função administrativa. Função jurisdicional. Projeto Victor. Novo Humanismo. Justiça Cidadã.

Artigo submetido em 18 de junho de 2020 e aprovado em 29 de agosto de 2020.

\footnotetext{
Doutora em Direito Pela Universidad de Deusto. Mestre pela University of London. Graduada pela Faculdade Mineira de Direito da PUC Minas. Professora da PUC Minas. Advogada. Email: annamartins@ @otmail.com.

*** Especialista em Direito Processual pelo Instituto de Educação Continuada da PUC Minas. Graduado em Direito pela Faculdade Mineira de Direito da PUC Minas. Professor da PUC Minas Virtual. Advogado. Email: jpalvesreis@hotmail.com.

* Mestrando no PPG em Filosofia da Universidade Federal de Minas Gerais (UFMG) com bolsa da Fundação de Amparo à Pesquisa do Estado de Minas Gerais (FAPEMIG). Bacharel em Direito pela Pontifícia Universidade Católica de Minas Gerais (PUC Minas). Email: lucas.s.andrade28@gmail.com.
} 


\begin{abstract}
Taking as a theoretical reference the model of Public Management, we tried to verify the contribution of artificial intelligence to the promotion of the new humanism and the ideal of Citizen Justice. To this end, we sought to assess whether the artificial intelligence mechanisms are aligned, in principle, to the Managerial Public Administration model, analyzing the compatibility of the Victor Project of the Supreme Federal Court (STF) with the principle of non-delegability of the jurisdictional function and the reflexes of the use of cognitive computing in the exercise of administrative and jurisdictional functions of the Brazilian Judiciary. Analyzing the results so far known from the Victor Project (STF), it remains to be demonstrated that cognitive computing mechanisms are compatible with the aforementioned Public Administration model, generating positive impacts on administrative and jurisdictional functions, without violating the latter's delegation prohibition. In this sense, it was concluded that artificial intelligence systems contribute to a better future for the Brazilian Judiciary and for the realization of the new humanism and the ideal of citizen Justice.
\end{abstract}

Keywords: Public Management Administration. Judicial power. Administrative function. Jurisdictional function. Victor Project. New Humanism. Citizen Justice.

\title{
INTRODUÇÃO
}

Em prefácio ao livro $A$ irrupção dos Movimentos Populares: Rerum novarum do nosso tempo, o Papa Francisco clama pela construção de um novo humanismo para combater os males de uma sociedade global ferida pelo medo, pela xenofobia, pelo racismo e por uma economia cada vez mais distante da ética. (VATICAN NEWS, 2019). Tal exortação é reforçada na mensagem de lançamento de um novo pacto educativo global, o qual, dentre outros objetivos, visa à formação de pessoas "capazes de construir um tecido de relações com as famílias, entre as gerações e com as várias expressões da sociedade civil, de modo a constituir um novo humanismo" (FRANCISCO, 2019).

Lucas Pydd Nechi (2017, p. 39) ensina que o “conceito 'humanismo' possui uma vasta e contraditória história, sendo utilizado por diversas correntes filosóficas". Todavia, de uma maneira geral, a dignificação do homem é o eixo fundamental de tais correntes (NOGARE, 1985, apud NECHI, 2017, p. 39). No atual contexto jurídico brasileiro, a busca dessa dignificação por meio de um novo humanismo deve levar em conta, indubitavelmente, o ideal de uma Justiça Cidadã, isto é, de um Poder Judiciário que seja capaz de oferecer ao jurisdicionado serviços públicos de qualidade e em tempo razoável. 
Dessa perspectiva, para a promoção de uma Justiça Cidadã (e, por consequência, de um novo humanismo), é de extrema relevância a discussão acerca do uso de mecanismos tecnológicos no âmbito do Judiciário brasileiro, como a inteligência artificial, realidade cada vez mais presente no mencionado Poder.

O presente trabalho é fruto da revisão, da atualização e da ampliação do artigo "Justiça Cidadã, Administração Pública Gerencial, Poder Judiciário e Inteligência Artificial: uma análise sobre o uso da computação cognitiva pelo Poder Judiciário brasileiro e os seus reflexos nas funções administrativa e jurisdicional à luz do Projeto Victor", laureado com a segunda colocação no I Concursos de Artigos Científicos do STJ, no eixo temático "Futuro da Justiça no Brasil”. .

Embora mantido como referencial teórico o modelo de Administração Pública Gerencial, o presente estudo foi oxigenado pelo clamor do Sumo Pontífice, pois a construção de um novo humanismo reivindica, como bem observado por Patrick Viveret (2000), um posicionamento crítico fundamentado em face das tecnologias originadas das revoluções da informática, como a computação cognitiva.

Manteve-se o enfoque no Projeto Victor do Supremo Tribunal Federal (STF), por duas razões. A primeira, porque tal projeto, como será visto, teve seu início quando o STF era presidido pela Ministra Cármen Lúcia Antunes Rocha, professora e egressa da Faculdade Mineira de Direito, sendo fundamental destacar, nas comemorações dos 70 (setenta) anos da "Casa de Lopes da Costa",2, a relevante contribuição de uma ilustre ex-aluna e atual docente

\footnotetext{
${ }^{1}$ A versão original do presente trabalho foi submetida ao I Concurso de Artigos do STJ em 12/07/2019 e o resultado da premiação foi divulgado em 06/09/19. Posteriormente, a referida versão foi publicada na Revista Científica do STJ, edição n. 1, de agosto de 2020, e está disponível no seguinte endereço eletrônico: https://ww2.stj.jus.br/publicacaoinstitucional/index.php/RCSTJ/issue/view/1789/showToc

${ }^{2}$ A Faculdade Mineira de Direito é conhecida como a "Casa de Lopes da Costa", referência carinhosa a um de seus mais notáveis fundadores e diretores. Segundo Hermes Vilchez Guerrero:
}

Alfredo de Araújo Lopes da Costa nasceu na cidade do Rio de Janeiro, em 15 de dezembro de 1885 e faleceu em 19 de abril de 1965. Estudou no Ginásio Nacional (D. Pedro II), no Rio de Janeiro. Formou-se em Letras, em 1902, começando a estudar Medicina e logo depois abandonando o curso para iniciar o de Direito na Faculdade Livre de Ciências Jurídicas e Sociais na mesma Cidade. Quando estudante, e mesmo depois de formado, exerceu o jornalismo, sendo um dos mais destacados defensores da campanha civilista de Rui Barbosa à presidência da República. Mudou-se para Minas Gerais para trabalhar com seu irmão, atuando como agrimensor em São Gotardo. Após isso começou a advogar em Carmo do Parnaíba, Patrocínio e no Estado de Goiás. Foi nomeado juiz pelo Presidente do Estado Mello Viana, a pedido do Professor Mendes Pimentel, em agosto de 1926. Só foi promovido a Desembargador quando Milton Campos assumiu o governo mineiro em 1948, aposentando-se em julho de 1953. É um dos fundadores da Faculdade 
Artigo: Novo Humanismo, Justiça Cidadã, Administração Pública Gerencial, Poder Judiciário e Inteligência Artificial: Uma análise sobre o uso da computação cognitiva pelo Poder Judiciário brasileiro e os seus reflexos nas funções administrativa e jurisdicional à luz do Projeto Victor

para um programa jurídico-tecnológico tão significativo. A segunda, por se tratar de uma pesquisa que tem como uma de suas metodologias o estudo de caso, é imperioso o acompanhamento diuturno da evolução e do atual estado de aplicabilidade do Projeto Victor (STF).

O objetivo geral do presente estudo é verificar a contribuição da inteligência artificial para a promoção de um novo humanismo e, naturalmente, para o ideal de Justiça Cidadã. Lado outro, os objetivos específicos são: examinar se os mecanismos de inteligência artificial estão alinhados, em princípio, ao modelo de Administração Pública Gerencial; aferir a compatibilidade do Projeto Victor (STF) com o princípio da indelegabilidade da função jurisdicional; analisar os reflexos da utilização da computação cognitiva no exercício das funções administrativa e jurisdicional do Poder Judiciário brasileiro e sua contribuição para um novo humanismo e para o ideal de Justiça Cidadã, levando em consideração as contribuições do Projeto Victor (STF).

Justifica-se a escolha do presente tema porque, embora sua abordagem seja relativamente nova no âmbito jurídico nacional, sua discussão é de extrema relevância, levando-se em conta os avanços significativos e a tendência de expansão do uso da inteligência artificial pelo mencionado Poder. Exemplo significativo de tal tendência foi a criação, no âmbito do Conselho Nacional de Justiça (CNJ), do Laboratório de Inovação para o Processo Judicial em meio Eletrônico - Inova PJe - e do Centro de Inteligência Artificial aplicada ao PJe, nos termos da Portaria CNJ n. 25, de 19 de fevereiro de 2019 (BRASIL, 2019).

Quanto à metodologia, trata-se de um trabalho de vertente jurídico-sociológica, vez que pretende aferir os efeitos do uso de programas de inteligência artificial pelo Poder Judiciário brasileiro para a construção de um novo humanismo e para a promoção da Justiça

Mineira de Direito (PUC-Minas), onde lecionou por muitos anos. (GUERRERO, 2017, p. 426).

Trata-se de um dos maiores processualistas da história do Brasil, "autor de um tratado institucional de direito processual civil que, embora escrito na vigência do Código de 1939, desafia a ação do tempo e é ainda hoje um dos melhores que já se escreveram em nosso país". (CINTRA; GRINOVER; DINAMARCO, 2008, p.144). Segundo Sálvio de Figueiredo Teixeira (2000, p. 111), poucos "processualistas brasileiros, ou talvez nenhum, tenha influenciado tanto a nossa doutrina processual civil brasileira". Pede-se vênia desde já por uma nota de rodapé mais longa do que a habitual, mas nos 70 anos desta ilustre Casa para qual tanto contribuiu, a referência a Lopes da Costa é uma homenagem justa e necessária, pois, sem sombra de dúvidas, foi um grande expoente do Direito que deixou o seu nome marcado "para sempre na vida jurídica do Estado, em especial no magistério e na magistratura”. (GUERRERO, 2017, p. 426). 
Cidadã. Fará uso do raciocínio indutivo, vez que, levando-se em consideração o Projeto Victor (STF), procurará aferir conclusões gerais a respeito dos impactos de tal ferramenta na eficiência das funções administrativa e jurisdicional do Poder Judiciário Brasileiro. Terá caráter multidisciplinar, vez que abordará, de forma integrada, conceitos atinentes à Engenharia de Software, Ciência da Computação, Gestão Pública, Direito Constitucional, Processual e Administrativo. A pesquisa empreenderá uma investigação prospectiva, visto que objetiva prever um cenário futuro em razão da expansão do uso da computação cognitiva pelo Poder Judiciário Brasileiro. Por isso, os métodos serão o teórico (bibliográfico) e o estudo de caso, já que a proposta de trabalho tem por enfoque avaliar a evolução e aplicabilidade do Projeto Victor (STF) para a promoção da Justiça Cidadã. (GUSTIN; DIAS, 2010).

O presente trabalho organizou-se da seguinte forma: inicialmente, procurou-se conceituar, de modo sucinto e não exaustivo, o termo "Administração Pública Gerencial", diferenciando-o do modelo de Administração Pública burocrática (seção 2) e relacionando-o com as funções administrativa e jurisdicional do Poder Judiciário (seção 3); em seguida, procurou-se discorrer sobre o conceito de Inteligência Artificial, diferenciando-o dos mecanismos de gestão processual (seção 4); ato contínuo, analisou-se o Projeto Victor (seção 5), a sua compatibilidade com o princípio da indelegabilidade da função jurisdicional, com o modelo de Administração Pública Gerencial e com o ideal de um novo humanismo e de Justiça Cidadã, concluindo-se afirmativamente (considerações finais).

Cumpre observar que o presente trabalho não pretende esgotar o tema, mas visa demonstrar que os sistemas de Inteligência Artificial, como o Victor, quando utilizados de maneira adequada, contribuem para o ideal de um novo humanismo e de uma Justiça Cidadã.

\section{ADMINISTRAÇÃO PÚBLICA GERENCIAL}

Estabelecidos os delineamentos gerais do assunto a ser tratado, é necessário discorrer sobre os parâmetros teóricos indispensáveis para a correta compreensão do presente trabalho. Nesse sentido, conceituar-se-á, de modo sucinto e não exaustivo, o termo "Administração Pública Gerencial”.

Entende-se como gerencial o modelo de Administração Pública que pauta a sua atividade para obtenção de resultados eficientes, procurando alcançar uma maior excelência 
Artigo: Novo Humanismo, Justiça Cidadã, Administração Pública Gerencial, Poder Judiciário e Inteligência Artificial: Uma análise sobre o uso da computação cognitiva pelo Poder Judiciário brasileiro e os seus reflexos nas funções administrativa e jurisdicional à luz do Projeto Victor

na prestação dos serviços públicos (OLIVEIRA, 2018). Nesse sentido, Luiz Carlos BresserPereira ensina que:

\begin{abstract}
Na década de 80, logo depois da eclosão da crise de endividamento internacional, o tema que prendeu a atenção de políticos e elaboradores de políticas públicas em todo o mundo foi o ajuste estrutural ou, em termos mais analíticos, o ajuste fiscal e as reformas orientadas para o mercado. Nos anos 90, embora o ajuste estrutural permaneça entre os principais objetivos, a ênfase deslocou-se para a reforma do Estado, particularmente para a reforma administrativa (BRESSER-PEREIRA, 1998, p. 21).
\end{abstract}

Acompanhando a referida tendência, no Brasil, "a reformulação do papel e do tamanho do Estado foi implementada na década de 1990, por meio de alterações legislativas importantes que liberalizaram a economia e efetivaram a desestatização" (OLIVEIRA, 2018, p. 11). Procurou-se, então, reformar o aparelho estatal brasileiro, restando consignadas as diretrizes da referida reformulação no Plano Diretor da Reforma do Aparelho do Estado (DI PIETRO, 2018). O referido documento foi elaborado pelo extinto Ministério da Administração e da Reforma do Estado (MARE) e aprovado pela Câmara de Reforma do Estado em 21 de setembro de 1995 (DI PIETRO, 2018), servindo como base para a Reforma Administrativa estabelecida pela Emenda Constitucional número 19, de 04 de junho de 1998 (OLIVEIRA, 2018), cujo principal objetivo "seria a transformação da administração pública burocrática pela administração pública gerencial” (DI PIETRO, 2018, p. 61).

É importante destacar que, embora seja associado com frequência ao neoliberalismo, o modelo de Administração Pública Gerencial não se confunde com tal doutrina socioeconômica, tampouco com ideais conservadores (BRESSER-PEREIRA, 1998).

Em relação à referida confusão, as lições de Luiz Carlos Bresser-Pereira são esclarecedoras:

Deve-se notar, porém, que a identificação de ajuste fiscal com conservadorismo ou neoliberalismo pode ter uma explicação histórica, mas não tem explicação lógica. $\mathrm{O}$ neoliberalismo surgiu de uma reação contra a crise fiscal do Estado e por isto passou a se identificar com cortes nos gastos e com o projeto de reduzir o "tamanho" do Estado. Logo, porém, tornou-se claro para as administrações social-democratas que o ajuste fiscal não era proposta de cunho ideológico, mas condição necessária para qualquer governo forte e efetivo. Este fato, somado à óbvia superioridade da administração pública gerencial sobre a burocrática, levou governos de diferentes orientações ideológicas a se envolverem em reformas administrativas, quase todas visando a duas metas: redução dos gastos públicos a curto prazo e aumento da eficiência mediante orientação gerencial, a médio prazo (BRESSER-PEREIRA, 1998, p.32). 
Em realidade, tal modelo de Administração Pública se opõe às respostas oferecidas pelo neoliberalismo para o enfrentamento da crise fiscal e estrutural do Estado, por considerar a proposta de um Estado Mínimo utópica. (PRESIDÊNCIA DA REPÚBLICA, 1995). Embora considere evidentes as limitações da intervenção estatal, Bresser-Pereira ensina que as políticas públicas exercem um papel tão grande e estratégico no capitalismo contemporâneo "que é irrealista propor que sejam substituídas pela coordenação do mercado, nos termos sugeridos pelo pensamento neoliberal” (BRESSER-PEREIRA, 1998, p.23), não passando de puro dogmatismo a ideia de que as falhas de mercado são menos graves que as do Estado (BRESSER-PEREIRA, 1998). Com efeito, os cidadãos, tanto em países desenvolvidos quanto em desenvolvimento, continuam a exigir mais do Estado (BRESSERPEREIRA, 1998), e tal realidade é ainda mais perceptível em um contexto de crise mundial como a ocasionada pela pandemia do coronavírus (COVID-19).

Lado outro, é necessário observar também que o modelo de Administração Pública Gerencial não refuta todas as diretrizes da Administração Pública Burocrática, conforme se depreende claramente da leitura do trecho abaixo do Plano Diretor de Reforma do Estado:

\begin{abstract}
A administração pública gerencial constitui um avanço e até um certo ponto um rompimento com a administração pública burocrática. Isto não significa, entretanto, que negue todos os seus princípios. Pelo contrário, a administração pública gerencial está apoiada na anterior, da qual conserva, embora flexibilizando, alguns dos seus princípios fundamentais, como a admissão segundo rígidos critérios de mérito, a existência de um sistema estruturado e universal de remuneração, as carreiras, a avaliação constante de desempenho, o treinamento sistemático. A diferença fundamental está na forma de controle, que deixa de basear-se nos processos para concentrar-se nos resultados, e não na rigorosa profissionalização da administração pública, que continua um princípio fundamental (PRESIDÊNCIA DA REPÚBLICA, 1995, p.16).
\end{abstract}

Em apertada síntese, o modelo de Administração Pública Gerencial se contrapõe ao arquétipo da Administração Pública Burocrática na medida em que esta é autorreferente, concentrando-se em processos, sem se preocupar com eventual ineficiência de sua atuação, enquanto aquela é voltada para o cidadão, preocupando-se com resultados concretos eficientes, servindo-se de diversos instrumentos, dentre os quais, o incentivo à criatividade e à inovação (BRESSER-PEREIRA, 1998), o que coincide com os propósitos e ideais de um novo humanismo e de uma Justiça Cidadã.

\title{
3 ADMINISTRAÇÃo PÚBLICA GERENCIAL E FUNÇÕES ADMINISTRATIVA E JURISDICIONAL DO PODER JUDICIÁRIO
}


Artigo: Novo Humanismo, Justiça Cidadã, Administração Pública Gerencial, Poder Judiciário e Inteligência Artificial: Uma análise sobre o uso da computação cognitiva pelo Poder Judiciário brasileiro e os seus reflexos nas funções administrativa e jurisdicional à luz do Projeto Victor

Conforme visto na seção anterior, o principal escopo do Plano Diretor da Reforma do Aparelho do Estado, que serviu como parâmetro para a Reforma Administrativa estabelecida pela Emenda Constitucional número 19, de 04 de junho de 1998, era a implementação do modelo de Administração Pública Gerencial no Estado brasileiro (DI PIETRO, 2018; OLIVEIRA, 2018).

Dentre as inúmeras alterações trazidas pela mencionada emenda constitucional, que não serão objeto de análise e pormenores em razão do enfoque do presente trabalho, destacase a inclusão da eficiência como princípio constitucional expresso da Administração Pública (artigo 37, caput, da Constituição de 1988). (BRASIL, 1988). Para Mendes e Blanco (2017), a inclusão princípio da eficiência de forma expressa no texto constitucional foi uma obviedade que, não obstante, foi aprovada por "quem compreendia, ao tempo da inclusão, a necessidade de se reafirmarem os pressupostos de exercício dos poderes administrativos" (MENDES; BLANCO, 2017, pp.901-902). Com efeito, conforme lições de José dos Santos Carvalho Filho:

\footnotetext{
Com a inclusão, pretendeu o Governo conferir direitos aos usuários dos diversos serviços prestados pela Administração ou por seus delegados e estabelecer obrigações efetivas aos prestadores. Não é difícil perceber que a inserção desse princípio revela o descontentamento da sociedade diante de sua antiga impotência para lutar contra a deficiente prestação de tantos serviços públicos, que incontáveis prejuízos já causou aos usuários. De fato, sendo tais serviços prestados pelo Estado ou por delegados seus, sempre ficaram inacessíveis para os usuários os meios efetivos para assegurar seus direitos. Os poucos meios existentes se revelaram insuficientes ou inócuos para sanar as irregularidades cometidas pelo Poder Público na execução desses serviços (CARVALHO FILHO, 2017, p.31).
}

O referido princípio objetiva, pois, alcançar a produtividade e a economicidade, exigindo o uso racional e adequado dos recursos públicos, bem como impondo a prestação de serviços públicos com presteza, qualidade e rendimento funcional (CARVALHO FILHO, 2017).

Dentro de tal perspectiva, o Poder Judiciário deve pautar-se pelos parâmetros da Administração Pública Gerencial, seja no desempenho de suas funções típicas quanto atípicas, notadamente a administrativa. Conforme observa Heloisa Monteiro de Moura Esteves (2011), há muito não incumbe ao Judiciário tão somente o exercício da Jurisdição. Na atualidade, além da função jurisdicional, o Poder Judiciário detém um sem-número de funções administrativas, gerindo seu próprio orçamento, realizando concursos para provimento de 
cargos de magistrados, servidores e para serventia de cartórios extrajudiciais, promovendo licitações etc. (ESTEVES, 2011). Sob tal ótica, importante destacar que, segundo o relatório “Justiça em Números 2019”, elaborado pelo Conselho Nacional de Justiça (CNJ), em 2018, as despesas totais do Poder Judiciário Brasileiro alcançaram o montante de R \$ 100,2 bilhões, o equivalente a $1,5 \%$ do Produto Interno Bruto (PIB) nacional (CONSELHO NACIONAL DE JUSTIÇA, 2020). Depreende-se facilmente da leitura de tais dados que o mencionado Poder, um dos mais caros do mundo (ROSA; GUASQUE, 2020), gere uma quantia significativa de recursos para prover suas atividades e serviços, o que requer uma estrutura administrativa adequada e uma atuação voltada para obtenção de resultados eficientes. Nesse sentido, considerando que "o Poder Judiciário figura como uma das instituições de maior impacto na determinação do nível e ritmo do desenvolvimento econômico em um país" (ROSA; GUASQUE, 2020, p.68), a otimização de seu aparato é uma tarefa constante e imperiosa, notadamente em um contexto de grave crise econômica e social, acentuadamente agravado pela pandemia do COVID-19, no qual o Brasil, em junho de 2020, atingiu a amarga taxa de desemprego de 13,3\% (GLOBO, 2020a) e uma estimativa de queda em torno de 8 a 10\% no segundo trimestre de 2020 (GLOBO, 2020b).

Lado outro, alinhada aos parâmetros da Administração Pública Gerencial, a emenda constitucional n. 45, de 30 de dezembro de 2004, introduziu expressamente o princípio da duração razoável do processo no rol de direitos e garantias fundamentais da Constituição de 1988 (artigo 5 ${ }^{\circ}$, inciso LXXVIII) (BRASIL, 1988). Mendes e Blanco (2017) noticiam que alguns autores já consideravam o direito à duração razoável do processo implícito na seara normativa do postulado da dignidade da pessoa humana, e na ideia de Estado de Direito, sendo certo que tal princípio já era adotado nas convenções internacionais de direitos humanos.

Tal princípio garante ao cidadão o direito fundamental a uma prestação jurisdicional sem dilações desnecessárias ou indevidas (NEVES, 2019), vedando a duração indefinida e desmesurada do processo (MENDES; BLANCO, 2017) e assegurando, em prazo razoável, a solução integral do mérito, incluído nessa, nos termos do artigo $4^{\circ}$ do Código de Processo Civil (CPC), a atividade executiva (BRASIL, 2015).

Todavia, conforme destaca Neves (2019), não se pode confundir duração razoável com celeridade processual a qualquer custo, uma vez que a tramitação de um processo de forma rápida nem sempre garante a qualidade da prestação jurisdicional. Nesse sentido, o 
Artigo: Novo Humanismo, Justiça Cidadã, Administração Pública Gerencial, Poder Judiciário e Inteligência Artificial: Uma análise sobre o uso da computação cognitiva pelo Poder Judiciário brasileiro e os seus reflexos nas funções administrativa e jurisdicional à luz do Projeto Victor

princípio em comento deve ser avaliado com os demais direitos fundamentais para que não se incorra em situações inconstitucionais, ilegais e, sobretudo, injustas (NEVES, 2019).

Sob tal ótica, o Poder Judiciário, no exercício de sua função típica, também deve ser eficiente (DIDIER JÚNIOR, 2017), pois o exercício de funções administrativas (atípicas) por tal Poder só tem razão de ser para que a função jurisdicional seja desempenhada de modo independente, adequado e em tempo razoável. Nesse sentido, segundo Fredie Didier Júnior (2018, p.116), eficiente "é a atuação que promove os fins do processo de modo satisfatório em termos quantitativos, qualitativos e probalísticos". Em outros termos, o processo jurisdicional deve propiciar aos cidadãos um serviço público barato e em tempo razoável, procurando-se obter o maior resultado com o mínimo de atividade processual (THEODORO JÚNIOR, 2016), procurando-se, sempre, efetivar o ideal de Justiça Cidadã e, também, de um novo humanismo.

\section{INTELIGÊNCIA ARTIFICIAL}

Realizado o delineamento teórico acerca da Administração Pública Gerencial e sua contextualização no âmbito do Poder Judiciário, é preciso discorrer sobre o conceito de inteligência artificial, o que não é tarefa fácil, uma vez que há dissenso entre os especialistas do assunto quanto à referida conceituação (MEDEIROS, 2019).

Segundo Ertel (2017), a dificuldade na definição de Inteligência Artificial (Artificial Intelligence) decorre do valor emocional subjacente ao termo. Por um lado, exige uma compreensão do conceito de inteligência, o qual revela o fascínio do ser humano pelo componente racional de suas formas de vida. Afinal, como uma importante tradição do pensamento humano sustenta, o que distingue os seres humanos como racionais é o fato de serem capazes de compreender e dar respostas às razões dadas por fatos no mundo (PARFIT, 2011, p. 31). De outra maneira, e levando a sério os desdobramentos da demarcação racionalista dos agentes humanos, dizer que um agente é racional pressupõe identificar neste agente a sua capacidade de articular razões inferencialmente, isto é, considerar no espaço lógico das razões os comprometimentos que tais razões demandam e as permissões inferenciais que elas fornecem (BRANDOM, 2009).

Nesse ponto, surgem questões como "afinal, o que é inteligência?"; "como a racionalidade dos agentes humanos estabelece um critério ou parâmetro para a inteligência?”, 
"como a racionalidade inferencial dos agentes humanos se relaciona com o funcionamento das estruturas biológicas do cérebro humano e quais limites ele impõe às possibilidades de se alcançar artificialmente alguns resultados que a racionalidade humana alcança?” Destarte, o entendimento dessas questões permite avaliar as condições de possibilidade da engenharia de máquinas que desempenham atividades inteligentes que tipicamente são desempenhadas por agentes humanos (MCCARTHY, 2006).

Por outro lado, a performance das atividades inteligentes por máquinas levanta também o problema da concepção e do imaginário em torno do caráter artificial da inteligência na qual elas operam. Dúvidas acerca da possibilidade de máquinas poderem reproduzir as capacidades e estado mentais empáticos, por exemplo, que tipicamente permeiam a agência humana, são amplamente abordados na literatura e no cinema de ficção científica. Isso pode ser observado nas histórias em que seres humanos são dominados pela inteligência artificial, como no caso da Skynet em Exterminador do Futuro e da ilusão da Matrix, a qual adormece os seres humanos enquanto eles servem de fonte energética para máquinas que eles mesmo criaram. Da mesma forma, o problema do artificial levanta reflexões de ordem filosófica, para a qual importantes filósofos naturalistas, como Dennett (DENNETT, 1991, 435-9) e Churchland (CHURCHLAND,1991), assumem a virada conceitual promovida pelo Jogo da Imitação ou Teste de Turing (TURING, 2009) como um critério que demarca a diferença entre uma simples máquina e uma máquina inteligente. Dennett, numa perspectiva darwiniana, assume que o curso evolutivo tornou os seres humanos "máquinas inteligentes" e os seus neurônios poderiam ser assumidos como microrrobôs funcionalmente eficientes (DENNETT, 2017). No entanto, apesar do desafiador universo que o tema revela, a proposta neste artigo não é uma reconstrução dos estudos em Inteligência Artificial ou apresentar uma solução para os problemas filosóficos que ela demanda, mas pensar a Inteligência Artificial e o seu impacto no exercício das funções administrativa e jurisdicional pelo Poder Judiciário brasileiro e seu desempenho na construção de um novo humanismo e de uma Justiça Cidadã. Para isso, assume-se a definição programática de Inteligência Artificial, tal como proposta por Mariusz Flasiński, que revela dois sentidos:

Em primeiro lugar, significa um campo comum de pesquisa em ciência da computação e robótica, no qual o desenvolvimento de sistemas que executam tarefas que requerem inteligência, quando realizado por seres humanos, é uma meta de pesquisa. Em segundo lugar, significa uma característica dos sistemas artificiais que 
Artigo: Novo Humanismo, Justiça Cidadã, Administração Pública Gerencial, Poder Judiciário e Inteligência Artificial: Uma análise sobre o uso da computação cognitiva pelo Poder Judiciário brasileiro e os seus reflexos nas funções administrativa e jurisdicional à luz do Projeto Victor

lhes permite realizar tarefas que exigem inteligência, quando feitas por seres humanos (FLASIŃSKI, 2016, p. 235, tradução livre). ${ }^{3}$

Assim, a inteligência artificial ou computação cognitiva é uma tecnologia que possibilita a computadores e equipamentos relacionados a capacidade de reter informações, processá-las e atuar a partir delas sem a necessidade de uma programação para tal desiderato (ATHENIENSE, 2018).

Os sistemas de inteligência artificial não se confundem com programas de gestão e tramitação de processos, como o Processo Judicial Eletrônico (PJE). Na computação cognitiva, as máquinas são capazes de desenvolver "processos análogos ao raciocínio humano com o objetivo de execução e automatização de tarefas que até então somente poderiam ser desempenhadas pelos próprios seres humanos" (MEDEIROS, 2019). Nesse sentido, Atheniense ensina que:

Essa habilitação ocorre em razão do sistema cognitivo das máquinas, que usam uma tecnologia capaz de processar informações, aprender com elas e melhorar o seu desemprenho, sem a necessidade de intervenção humana. Por meio desse sistema, um computador é capaz de tomar decisões baseadas nas informações por ele processadas e em experiências anteriores, o que implica em constante melhoramento e auto-aprendizado, de forma semelhante ao que acontece no cérebro humano (ATHENIENSE, 2018).

Todavia, conforme bem pontuado pelo juiz Bráulio Gusmão no XII Encontro Nacional do Poder Judiciário, realizado em 04/12/2018, "soluções de IA andam em paralelo com a ciência dos dados, disciplina que mostra como utilizar ferramentas, métodos e tecnologia para analisar, visualizar e tomar decisões", destacando ainda o referido magistrado que quanto "maior a diversidade dos dados ou a falta de padronização na sua produção, maior será a dificuldade para aprendermos com eles, uma vez que será necessário um esforço prévio de "higienização" (CONSELHO NACIONAL DE JUSTIÇA, 2018a). Em outros termos, mecanismos de gestão e tramitação de processos (como o PJE) e sistemas de inteligência artificial não são realidades estanques: estes necessitam daqueles para um correto funcionamento.

\footnotetext{
3 No original: "Firstly, it means a common research field of computer science and robotics, 2 in which development of systems performing tasks which require intelligence when performed by humans is a research goal. Secondly, it means a feature of artificial systems which allows them to perform tasks that require intelligence, when made by humans".
} 
Conforme leciona Renato Vasconcelos Magalhães (2005), os estudos sobre inteligência artificial aplicada ao Direito, com exceção de alguns trabalhos vanguardistas, sugiram aproximadamente na década de 70 do século XX, "quando a comunidade jurídica começou a despertar maior interesse pelos processos de automatização do raciocínio jurídico" (MAGALHÃES, 2005). No âmbito jurídico brasileiro, o interesse pela referida temática é relativamente recente. Todavia, conforme pontuado na introdução do presente trabalho, sua discussão é de extrema relevância, tendo em vista os significativos avanços e a tendência expansão do uso da computação cognitiva no mundo jurídico nacional, notadamente pelo Poder Judiciário.

Recentemente, inúmeras ferramentas de computação cognitiva foram desenvolvidas para atendimento de atividades relacionadas à esfera do mencionado Poder (MEDEIROS, 2019), não sendo possível abordar todas no presente trabalho. Em razão disso, dar-se-á enfoque ao Projeto Victor (STF), que será abordado de maneira mais detida a partir da seção seguinte.

Antes de passar à análise do referido Projeto, é preciso destacar que o uso da Inteligência Artificial no âmbito jurídico é um tema da moda, e como tal, gera muitas expectativas e temores.

Com efeito, o uso da computação cognitiva e de outras tecnologias digitais estão inseridos em um processo de transformação revolucionário, já alçado ao nível de $4^{\mathrm{a}}$ Revolução Industrial ou Revolução 4.0. (ROSA; GUASQUE, 2020). Tal transformação, ao adentrar na esfera jurídica, cria a legítima expectativa de ofertar expedientes e "ferramentas úteis ao aprimoramento da atividade jurisdicional" (ROSA; GUASPE, 2020, p.67). Por outro lado, há uma preocupação, igualmente justificável, quantos aos impactos que uma revolução como essa pode gerar com a utilização de máquinas em substituição da mão de obra humana em larga escala, como de fato já vem ocorrendo, inclusive, na seara do Direito (ATHENIENSE, 2018). Em palestra proferida no HSM Expo 2019, ocorrida em São Paulo, Yuval Harari ressaltou que:

\footnotetext{
A inteligência artificial e a robótica vão mudar profissões e muitos dos trabalhos que as pessoas fazem hoje vão desaparecer. Novos vão emergir, mas nós não sabemos se trabalhos suficientes vão ser criados (COMPUTER WORLD, 2019).
}

Diante de um cenário de incertezas e, por consequência, de posições extremadas, "há sempre lugar para uma posição moderada, termo médio que represente o aproveitamento harmônico 
Artigo: Novo Humanismo, Justiça Cidadã, Administração Pública Gerencial, Poder Judiciário e Inteligência Artificial: Uma análise sobre o uso da computação cognitiva pelo Poder Judiciário brasileiro e os seus reflexos nas funções administrativa e jurisdicional à luz do Projeto Victor

da energia dessas forças contrárias (...)” (CUNHA; CINTRA, 2008, p.7) ${ }^{4}$, quais sejam, daqueles que concebem a inteligência artificial como a solução para todos os males da Justiça e daqueles que a enxergam com um niilismo, por assim dizer, apocalíptico. Dentro de tal perspectiva, assiste razão a Alexandre Morais da Rosa e à Bárbara Guasque, os quais, lucidamente, lecionam que:

a revolução digital é um caminho sem volta e que, inexoravelmente, terá que ser percorrido por todas as ciências e sociedades. Logo, ao invés de resistir à mudança inevitável, deve-se descobrir a melhor maneira de trilhar essa senda, tirando-lhe o melhor em benefício da justiça e da coletividade (ROSA; GUASQUE, 2020, p. 67).

Nesse sentido, cumpre destacar que a Faculdade Mineira de Direito da Pontifícia Universidade Católica de Minas Gerais, seguindo as diretrizes de uma educação voltada para a concretização de um novo humanismo e os passos vanguardistas deixados por Dom Cabral ${ }^{5}$, pelo saudoso Lopes da Costa ${ }^{6}$ e por inúmeros outros colaboradores de prol, está contribuindo decisivamente para a pavimentação de uma "trilha" tecnológica voltada para melhor atender a Justiça e a Coletividade através de iniciativas como as do Núcleo Acadêmico de Pesquisa (NAP), que tem uma linha de investigação denominada "Lógica, Direito e Inteligência Artificial”.

\footnotetext{
${ }^{4}$ A lição acima citada foi extraída da aclamada "Nova Gramática do Português Contemporâneo", dos notáveis filólogos Celso Cunha e Lindley Cintra. Tal ponderação está inserida na discussão envolvendo os gramáticos que defendem o rompimento com as tradições clássicas da língua e os que estão arraigados em velhas concepções gramaticais. (CUNHA; CINTRA, 2008). Por representar uma posição intelectualmente equilibrada, tal ensinamento merece ser transposto para a debate relativo aos riscos e às possibilidades envolvendo o uso da computação cognitiva e de outras tecnologias disruptivas.

${ }^{5}$ Segundo Hermes Vilchez Guerrero:
}

Dom Antônio dos Santos Cabral nasceu em Propriá, Sergipe, em 8 de outubro de 1884 e faleceu em Belo Horizonte, no dia 15 de novembro de 1967. Ordenado padre, em 1907, em 1918 foi consagrado bispo de Natal/RN. Criou o Seminário Provincial do Coração Eucarístico, instalou a Catedral da Boa Viagem, realizou o Congresso Eucarístico Nacional de 1936, criou o jornal O Diário, em 1935, e fundou a Universidade Católica de Minas Gerais. (GUERRERO, 2017, P.334).

Com efeito, a PUC Minas é "fruto do sonho de um homem, conhecido e eternizado pelo bairro que leva o seu nome: Dom Antônio dos Santos Cabral, o Dom Cabral”. (PONTIFÍCIA UNIVERSIDADE CATÓLICA DE MINAS GERAIS, 2020). A presente nota de rodapé, sabidamente longa, é uma homenagem igualmente justa e necessária para alguém que tanto fez para Belo Horizonte, para Minas Gerais e pelo Brasil.

${ }^{6}$ Para uma pequena biografia deste notável jurista brasileiro e fundador da Faculdade Mineira de Direito, ver nota de rodapé n. 5, supra. 
Realizadas as considerações acima, abordar-se-á na seção seguinte o Projeto Victor (STF), iniciado, conforme visto, durante a presidência da Ministra Cármen Lúcia Antunes Rocha, egressa e professora da "Casa de Lopes da Costa".

\section{PROJETO VICTOR (STF)}

O Projeto Victor é fruto de uma parceria entre o STF e a Universidade de Brasília (UNB), tratando-se "de projeto que envolve a parceria entre três cursos da UnB: Direito, Engenharia de Software e Ciência da Computação" (MAIA FILHO; JUNQUILHO, 2018).

O seu nome é uma homenagem a Victor Nunes Leal, ex-ministro do STF, que teve importante papel na organização e sistematização da jurisprudência do referido Tribunal (SUPREMO TRIBUNAL FEDERAL, 2018). Conforme lecionam Maia Filho e Junquilho, o projeto tem por escopo:

a aplicação de métodos de aprendizado computacional de máquina com o objetivo de usar seus potenciais no reconhecimento de padrões nos processos jurídicos relativos a julgamentos de repercussão geral do STF (MAIA FILHO; JUNQUILHO, 2018).

O Projeto Victor teve o seu início anunciado em 30/08/2018 pela então Presidente do STF, Ministra Cármen Lúcia (SUPREMO TRIBUNAL FEDERAL, 2018). Na referida ocasião, a Ministra explicou que a ferramenta foi desenvolvida para a execução de quatro atividades: conversão de imagens em textos no processo digital, separação do começo e do fim de um documento (peça processual, decisão etc.) em todo o acervo do Tribunal, separação e classificação das peças processuais mais utilizadas nas atividades do STF e a identificação dos temas de repercussão geral de maior incidência (SUPREMO TRIBUNAL FEDERAL, 2018). A título exemplificativo, a Ministra Cármen Lúcia ressaltou que o trabalho de conversão de imagens em texto que um servidor executa em três horas, seria feito em cinco segundos com a nova ferramenta (SUPREMO TRIBUNAL FEDERAL, 2018).

Ainda sobre o Projeto Victor, em 23/10/2018, em painel do I Seminário de Processo Civil da Associação dos Juízes Federais do Brasil (Ajufe) e do Instituto Brasileiro de Direito Processual (IBDP), o atual Presidente do STF, Ministro Dias Toffoli, informou que os testes até então realizados indicaram que o Projeto Victor identifica os casos de recursos extraordinários ou de agravo em recursos extraordinários com acuidade de $85 \%$, ressaltando 
Artigo: Novo Humanismo, Justiça Cidadã, Administração Pública Gerencial, Poder Judiciário e Inteligência Artificial: Uma análise sobre o uso da computação cognitiva pelo Poder Judiciário brasileiro e os seus reflexos nas funções administrativa e jurisdicional à luz do Projeto Victor

que trabalho que custaria ao servidor de um tribunal entre 40 minutos e uma hora para fazer, o software faz em cinco segundos (CONSELHO NACIONAL DE JUSTIÇA, 2018b).

Os fatos acima narrados endossam o que já foi dito na seção 4 do presente trabalho: o uso da inteligência artificial no Direito, notadamente pelo Poder Judiciário, já é uma realidade merecedora de detida atenção. Tanto é verdade que, conforme destacado na introdução do presente trabalho (seção 1), o CNJ criou, por meio da Portaria CNJ n. 25, de 19 de fevereiro de 2019, o Laboratório de Inovação para o Processo Judicial em meio Eletrônico - Inova PJe - e o Centro de Inteligência Artificial aplicada ao PJe (BRASIL, 2019). Conforme destacado pelo magistrado Bráulio Gusmão no XII Encontro Nacional do Poder Judiciário, realizado em 04/12/2018, o "alto custo da capacidade de processamento das informações, bem como a necessidade de formação de profissionais que possam trabalhar adequadamente nessas áreas fez que o CNJ assumisse a frente desse processo" (CONSELHO NACIONAL DE JUSTIÇA, 2018a).

Nesse sentido, é muito provável que, em médio ou curto prazo, haverá um impacto significativo tanto na estrutura do Poder Judiciário quanto no exercício de suas funções administrativa e jurisdicional, o que será abordado na seção a seguir.

\section{PROJETO VICTOR, ADMINISTRAÇÃO GERENCIAL, NOVO HUMANISMO E JUSTIÇA CIDADÃ}

Antes de se desenvolver os argumentos principais acerca dos reflexos da utilização da computação cognitiva no exercício das funções administrativa e jurisdicional do Poder Judiciário brasileiro e sua contribuição para o ideal de um novo humanismo e de uma Justiça Cidadã, é necessário tecer argumentos secundários acerca da compatibilidade do Projeto Victor ao princípio da indelegalidade da função jurisdicional.

Em razão de tal princípio, não pode "o órgão jurisdicional delegar funções a outro sujeito" (DIDIER, 2017, p.198), com exceção de atos de administração e de mero expediente sem caráter decisório, nos termos do artigo 93, inciso XIV, da Constituição de 1988, bem como do artigo 152, inciso VI, do Código de Processo Civil (BRASIL, 1988; BRASIL, 2015).

Nesse sentido, entende-se no presente trabalho que o Projeto Victor não fere o princípio da indelegabilidade da função jurisdicional. Embora tal ferramenta exerça cognição propriamente dita, é cediço que as atividades desenvolvidas - conversão de imagens em textos no processo digital, separação do começo e do fim de um documento (peça processual, 
decisão, etc.) em todo o acervo do Tribunal, separação e classificação das peças processuais mais utilizadas nas atividades do STF e a identificação dos temas de repercussão geral de maior incidência - são de caráter meramente instrumental, que auxiliam os magistrados na elaboração de seus provimentos judiciais. Conforme ensinam Maia Filho e Junquilho:

\begin{abstract}
O objetivo do projeto não é que o algoritmo tome a decisão final acerca da repercussão geral, mas sim que, com as máquinas "treinadas" para atuar em camadas de organização dos processos, os responsáveis pela análise dos recursos possam identificar os temas relacionados de forma mais clara e consistente (STF, 2018). Isso vai gerar, em consequência, mais qualidade e velocidade ao trabalho de avaliação judicial, com a redução das tarefas de classificação, organização e digitalização de processos (MAIA FILHO; JUNQUILHO, 2018).
\end{abstract}

Esclarecida a premissa acima, os argumentos principais desenvolvidos na presente proposta de trabalho são favoráveis ao uso da inteligência artificial pelo Poder Judiciário brasileiro, obviamente, desde que as diretrizes do novo humanismo e do ideal de Justiça Cidadã sejam sempre observadas.

Com efeito, levando em consideração os resultados alcançados até agora pelo Projeto Victor (STF), verifica-se que os sistemas de computação cognitiva estão alinhados ao modelo de Administração Pública Gerencial, colaborando para que o Poder Judiciário exerça suas funções administrativas de maneira mais eficiente, uma vez que propicia um melhor aproveitamento de recursos materiais e humanos do STF, conforme bem ressaltado pela Ministra Cármen Lúcia (SUPREMO TRIBUNAL FEDERAL, 2018). Nesse sentido, estimase que o Projeto Victor (STF) pode gerar uma economia em torno de R 2 milhões anuais, além de otimizar a performance geral em toda a tramitação do processo judicial (SILVA; BRAZ; FERRETTI; CASTRO, 2019).

Igualmente, a referida ferramenta contribui positivamente para que o Poder Judiciário tenha um desempenho eficiente, adequado e em tempo razoável no exercício de sua função jurisdicional, pois, conforme destacado pela referida Ministra, o Projeto Victor contribui para o aceleramento da análise dos processos e reduz o congestionamento na admissibilidade dos recursos nos tribunais de origem, auxiliando o Poder Judiciário a cumprir sua missão em diversas instâncias. (SUPREMO TRIBUNAL FEDERAL, 2018). Todavia, considerando que tal ferramenta é ainda muito recente, não havendo por ora dados estatísticos consolidados acerca de seu funcionamento, assiste razão a Mariana Dionísio Andrade, a qual, ponderadamente, afirma que: 


\begin{abstract}
o ideal é acompanhamento detalhado da aplicação do Projeto Victor para observar as mudanças e impactos na distribuição e reconhecimento de classes processuais, em específico o recurso extraordinário com reconhecimento de repercussão geral, pois, assim, não geraria a aceitação acrítica da implementação do sistema sem uma política de impacto quanto à consecução de princípios e possíveis mudanças na gestão do tribunal (ANDRADE, 2020, p.332).
\end{abstract}

Por fim, o uso da computação cognitiva no Projeto Victor contribui para o incentivo à criatividade e à inovação no âmbito do Poder Judiciário Brasileiro, propiciando ao cidadão, destinatário principal do modelo de Administração Pública Gerencial, do novo humanismo e do ideal de Justiça Cidadã, uma prestação jurisdicional de excelência e em tempo razoável, obtendo-se, assim, um melhor resultado com o mínimo de atividade processual. Dentro de tal perspectiva, é indubitável que "o projeto VICTOR se consolidou como um marco importante da aplicação de IA no cenário jurídico-judicial brasileiro" (SILVA; BRAZ; FERRETTI; CASTRO, 2019, p.52).

\title{
CONSIDERAÇÕES FINAIS
}

O presente trabalho verificou que a inteligência artificial é uma tecnologia que pode promover as diretrizes do novo humanismo e do ideal de Justiça Cidadã, estando alinhada ao modelo de Administração Pública Gerencial.

Constatou-se que o Projeto Victor não ofende o princípio da indelegabilidade da função jurisdicional, uma vez que o referido sistema exerce atividades cognitivas de caráter meramente instrumental, gerando reflexos positivos no exercício das funções administrativa e jurisdicional.

Quanto à função administrativa, o referido Projeto colabora para que o Poder Judiciário exerça suas funções administrativas de maneira mais eficiente, propiciando o melhor aproveitamento de recursos materiais e humanos do STF.

Quanto à função jurisdicional, o mencionado Projeto contribui para uma prestação jurisdicional de excelência e em tempo razoável, obtendo-se, assim, um melhor resultado com o mínimo de atividade processual.

Todavia, é preciso destacar que o presente trabalho não esgota o tema, uma vez que o Projeto Victor é ainda muito recente, não havendo por ora dados estatísticos consolidados acerca de seu funcionamento. Assim, é imperioso o acompanhamento diuturno da evolução de tal ferramenta, sendo certo que iniciativas como as do NAP, que tem uma linha de 
investigação denominada "Lógica, Direito e Inteligência Artificial", são fundamentais para aferir a correta funcionalidade do Projeto Victor, bem como de outros mecanismos de Inteligência Artificial aplicados ao Direito, observando-se, é claro, as diretrizes de um novo humanismo e do ideal de Justiça Cidadã, valores inegociáveis da PUC Minas e da Casa de Lopes da Costa.

Nesse sentido, analisando os resultados até agora conhecidos do Projeto Victor (STF), conclui-se que mecanismos de computação cognitiva contribuem para um futuro melhor do Poder Judiciário brasileiro e para a concretização do novo humanismo e do ideal de Justiça Cidadã.

\section{REFERÊNCIAS}

ANDRADE, Mariana Dionísio. Inteligência artificial para o rastreamento de ações com repercussão geral: o projeto victor e a realização do princípio da razoável duração do processo. Revista Eletrônica de Direito Processual - REDP, v. 21, n. 1, p. 312-335, jan./abr. 2020. Disponível em: https://www.epublicacoes.uerj.br/index.php/redp/article/view/42717. Acesso em: 24 ago. 2020.

ATHENIENSE, Alexandre. A Inteligência Artificial e o Direito. Disponível em: http://alexandre-atheniense.jusbrasil.com.br/artigos/467690643/a-inteligenciaartificiale-o-direito. Acesso em: 16 ago. 2018.

BRANDOM, Robert. Articulating reasons: An introduction to inferentialism. Cambridge, Mass: Harvard University Press, 2009.

BRASIL. Novo Código de Processo Civil: comparado/Lei 13.105/2015. Coordenação Luiz Fux; Organização Daniel Amorim Assumpção Neves. $2^{a}$ ed. revista. Rio de Janeiro: Forense: São Paulo: Método, 2015.

BRASIL. Conselho Nacional de Justiça. Portaria n. 25 de 19/02/2019, que institui o Laboratório de Inovação para o Processo Judicial em meio Eletrônico - Inova PJe e o Centro de Inteligência Artificial aplicada ao PJe e dá outras providências. Diário de Justiça Eletrônico (CNJ), Brasília, n.35, 22 fev. 2019. Disponível em: https://atos.cnj.jus.br/atos/detalhar/2829. Acesso em: 18 ago. 2020.

BRASIL. Constituição (1988). Constituição da República Federativa do Brasil. Código 4 em 1. 9a ed. São Paulo: Saraiva, 2013.

BRESSER-PEREIRA, Luiz Carlos. Gestão do Setor Público: estratégia e estrutura para um novo Estado. In: Bresser-Pereira, Luiz Carlos e Peter Spink (orgs.). Reforma do Estado e Administração Pública Gerencial. Rio de Janeiro: Editora Fundação Getúlio Vargas, 1998.

CARVALHO FILHO, José dos Santos. Manual de direito administrativo. 31. ed. São Paulo: Atlas, 2017. 
CHURCHLAND, Paul M.; CHURCHLAND, Patricia Smith. Could a machine think?. Scientific American, v. 262, n. 1, p. 32-39, 1990.

COMPUTER WORLD. Yuval Harari: Inteligência Artificial pode criar uma geração de inúteis. Disponível em: https://computerworld.com.br/2019/11/05/yuval-harari-inteligenciaartificial-pode-criar-uma-geracao-de-inuteis/. 2019. Acesso em: 24 ago. 2020

CONSELHO NACIONAL DE JUSTIÇA. Relatório Justiça em Números 2020. Disponível em: https://www.cnj.jus.br/wp-content/uploads/2020/08/WEB-V3-Justi\%C3\%A7a-emN\%C3\%BAmeros-2020-atualizado-em-25-08-2020.pdf. Acesso em: 16 ago. 2020.

CONSELHO NACIONAL DE JUSTIÇA. CNJ anuncia a criação de laboratório de inteligência artificial para o PJe. 2018a. Disponível em: https://www.cnj.jus.br/cnj-anunciaa-criacao-de-laboratorio-de-inteligencia-artificial-para-o-pje/. Acesso em: 13 ago. 2020.

CONSELHO NACIONAL DE JUSTIÇA. Inteligência artificial: Trabalho judicial de 40 minutos pode ser feito em 5 segundos. Disponível em:

http://www.cnj.jus.br/noticias/cnj/87869-inteligencia-artificial-trabalho-judicial-de-40minutos-pode-ser-feito-em-5-segundos. Acesso em: $12 \mathrm{dez} .2018 \mathrm{~b}$.

CHURCHLAND, Paul M.; CHURCHLAND, Patricia Smith. Could a machine think?. Scientific American, v. 262, n. 1, p. 32-39, 1990.

CINTRA, Antônio Carlos de Araújo; GRINOVER, Ada Pellegrini; DINAMARCO, Cândido Rangel. Teoria Geral do Processo. $28^{\mathrm{a}}$ Ed. São Paulo: Malheiros, 2008.

CUNHA, Celso; CINTRA, Luís F. Lindley. Nova gramática do português contemporâneo. $5^{\text {a }}$ Ed. Rio de Janeiro: Lexikon, 2008.

DENNETT, Daniel C. Consciousness explained. Nova Iorque: Back Bay Books 1991.

DENNETT, Daniel C. From bacteria to Bach and back: The evolution of minds. Nova Iorque: WW Norton \& Company, 2017.

Desemprego sobe para 13,3\% em junho e país tem nova queda recorde no número de ocupados. Globo, Rio de Janeiro, 06 ago. 2020. Disponível em:

https://g1.globo.com/economia/noticia/2020/08/22/pib-do-2o-trimestre-trararecessao-recordeanalistas-veem-recuperacao-do-nivel-pre-pandem.... Acesso em: 22 ago. 2020a.

DIDIER JÚNIOR, Fredie. Curso de Direito Processual Civil. 19ª ed. Salvador: Editora JusPodivm, 2017.

DI PIETRO, Maria Sylvia Zanella. Direito administrativo. $31^{\text {a }}$ ed. Rio de Janeiro Forense: 2018. 
ERTEL, Wolfgang. Introduction to artificial intelligence. Cham: Springer International Publishing, 2017.

ESTEVES, Heloísa Monteiro de Moura. A representação do Poder Judiciário em juízo. In: Estado de Minas. Caderno Direito e Justiça, Belo Horizonte, p. 3, 10 out. 2011.

FLASIŃSKI, Mariusz. Introduction to artificial intelligence. Cham: Springer International Publishing, 2016.

FRANCISCO. Uma aliança educativa para um novo humanismo. 2019. Disponivel em: https://portugues.clonline.org/not\%C3\%ADcias/igreja/2019/09/20/papa-francisco-pactoeducativo-14-maio-2020. Acesso em: 18 ago. 2020.

GUERRERO, Hermes Vilchez. O casarão da Praça da República: a Faculdade Livre de Direito de Minas Geraes (1892-1930). Belo Horizonte: Del Rey, 2017.

GUSTIN, Miracy Barbosa de Sousa; DIAS, Maria Tereza Fonseca. (Re)pensando a pesquisa jurídica: teoria e prática. $3^{\text {a }}$ ed. rev. e atual. Belo Horizonte: Del Rey, 2010.

MAIA FILHO, Mamede Said; JUNQUILLO, Tainá Aguiiar. Projeto Victor: perspectivas de aplicação da inteligência artificial ao Direito. R. Dir. Gar. Fund., Vitória, v. 19, n. 3, p. 219238, set./dez. 2018. Disponível em:

http://sisbib.emnuvens.com.br/direitosegarantias/article/view/1587. Acesso em: 15 abr. 2019.

MAGALHÃES, Renato Vasconcelos. Inteligência Artificial e Direito - Uma Breve Introdução Histórica. Revista Direito e Liberdade, v. 1, n.1, p. 355-370 - jul/dez 2005.

MCCARTHY, John et al. A proposal for the dartmouth summer research project on artificial intelligence, august 31, 1955. AI magazine, v. 27, n. 4, p. 12-12, 2006.

MEDEIROS, Nathália Roberta Fett Viana de. Uso da inteligência artificial no processo de tomada de decisões jurisdicionais : uma analise sob a perspectiva da teoria normativa da comparticipação. 2019 Dissertação (Mestrado) - Pontifícia Universidade Católica de Minas Gerais, Programa de Pós-Graduação em Direito. Disponível em:http://www.biblioteca.pucminas.br/teses/Direito_MedeirosNRFV_1.pdf. Acesso em: 15 abr. 2019.

MENDES, Gilmar Ferreira; BRANCO, Paulo Gustavo Gonet. Curso de direito constitucional. 12. ed. rev. e atual. São Paulo: Saraiva, 2017.

NECHI, Lucas Pydd. O novo humanismo como princípio de sentido da didática da história: reflexões a partir da consciência histórica de jovens ingleses e brasileiros 2017 Tese (Doutorado) - Universidade Federal do Paraná, Programa de Pós-Graduação em Educação. Disponível em: https://acervodigital.ufpr.br/bitstream/handle/1884/46360/R\%20\%20T\%20-\%20LUCAS\%20PYDD\%20NECHI.pdf?sequence=1\&isAllowed=y. Acesso em: 16 ago. 2020.

NEVES, Daniel Amorim Assumpção. Manual de Direito Processual Civil. 11. ed. rev. e atual. São Paulo, Salvador: JusPodivm, 2017 
OLIVEIRA, Rafael Carvalho Rezende. Curso de direito administrativo. $6^{\mathrm{a}}$ ed. Rio de Janeiro: Método, 2018.

PARFIT, Derek. On what matters: volume one. Oxford: Oxford University Press, 2011.

PIB do $2^{\circ}$ trimestre trará recessão recorde; analistas veem recuperação do nível pré-pandemia só em 2022. Globo, Rio de Janeiro, 22 ago. 2020. Disponível em:

https://g1.globo.com/economia/noticia/2020/08/22/pib-do-2o-trimestre-trara-recessaorecorde-analistas-veem-recuperacao-do-nivel-pre-pandem.... Acesso em: 22 ago. 2020b.

PRESIDÊNCIA DA REPÚBLICA. Plano Diretor da Reforma do Aparelho do Estado. Brasília: 1995. Disponível em:

http://www.bresserpereira.org.br/documents/mare/planodiretor/planodiretor.pdf. Acesso em: 16 ago. 2020.

ROSA, Alexandre Morais da; GUASQUE, Bárbara. O avanço da disrupção nos tribunais brasileiros. In: Dierle Nunes, Paulo Henrique dos Santos Lucon e Erik Navarro Wolkat (orgs.).Inteligência Artificial e Direito Processual: os impactos da virada tecnológica no direito processual. Salvador: Editora Juspodivm, 2020.

SILVA, Nilton Correia da; BRAZ, Fabricio Ataides; FERRETTI, Jose Roberto Pimenta Ferretti; CASTRO; Clenys Reges Rosario Pereira de. Aplicação da Inteligência Artificial no sistema jurídico brasileiro: VICTOR e ALEI. Revista de Administración Pública del GLAP, v. 3, n. 5, p. 45-55, 2019. Disponível em: https://www.epublicacoes.uerj.br/index.php/redp/article/view/42717. Acesso em: 24 ago. 2000.

SUPREMO TRIBUNAL FEDERAL. Ministra Cármen Lúcia anuncia início de funcionamento do Projeto Victor, de inteligência artificial. Disponível em: http://www.stf.jus.br/portal/cms/verNoticiaDetalhe.asp?idConteudo=388443. Acesso em: 12 dez. 2018.

TEIXEIRA, Sálvio de Figueiredo. Lopes da Costa e o processo civil brasileiro. Revista de Informação Legislativa, v. 37, n. 148, p. 219-238, out./dez. 2000. Disponível em: https://www2.senado.leg.br/bdsf/bitstream/handle/id/632/r14806.pdf? sequence $=4 \&$ isAllowed=y. Acesso em: 24 ago. 2020.

THEODORO JÚNIOR, Humberto. Curso de Direito Processual Civil, v.1, 57 a ed. Rio de Janeiro: Forense, 2016.

TURING, Alan M. Computing machinery and intelligence. In: Parsing the Turing Test. Springer, Dordrecht, 2009. p. 23-65.

VATICAN NEWS. Papa Francisco clama por um novo humanismo. 2019. Disponível em: https://www.vaticannews.va/pt/papa/news/2019-08/papa-francisco-prefacio-livro-movimentopopulares-humanismo.html. Acesso em: 13 ago. 2020. 
VIVERET, Patrick. É hora de um novo humanismo. Le Monde Diplomatique Brasil (acervo online) fev. 2000. Disponível em: https://diplomatique.org.br/e-hora-de-um-novohumanismo/. Acesso em: 13 ago. 2020. 